\title{
Efficacy/ Validity of Neck Dissection and Radiotherapy for Cervical Nodal Disease - Clinicopathological Analysis
}

\author{
Mumtaz Ahmad Umar ${ }^{1}$, Jawwad Ahmed ${ }^{2}$, Ghulam Saqulain ${ }^{3}$ \\ ${ }^{1}$ ENT Specialist, Shifa College of Medicine, Islamabad, Pakistan \\ ${ }^{2}$ Associate Surgeon ENT department, Capital Hospital, Islamabad, Pakistan \\ ${ }^{3}$ Head of Department of ENT, Capital Hospital, Islamabad, Pakistan
}

\section{ABSTRACT}

Objective: To analyze treated head and neck malignancies with reference to frequency of cervical metastases and frequency of nodal recurrence following neck dissection and/ or radiotherapy for cervical metastases.

Patients and Methods: This observational prospective study was conducted at ENT Department, Pakistan Institute of Medical Sciences, Islamabad over a period of 16 months. Study population was comprised of 15 cases of either gender and any age, with treated head and neck primary who developed metastatic neck disease and were included through non-probability sampling technique. Patients with primary site recurrence or distant metastases were excluded from the study. They were treated with neck dissection, radiotherapy or both for neck disease and followed up for a 1 year. Clinical data including age, gender, site and histopathology of treated primary tumor, nodal involvement both clinical and histopathological, treatment and post treatment result were recorded. Data was collected, tabulated and analyzed using Microsoft excel worksheet.

Results: Out of total 15 cases, $17 \%$ patients were with N1 disease, 33\% patients with N2a disease, and 50\% were with N2b disease. Total 3 (20\%) patients received radiotherapy (2 being unfit for surgery and 1 due to refused consent) and $12(80 \%)$ patients underwent surgery. Out of these 12, 3 underwent RND, 7 MRND and 2 SND. Total $20 \%$ (3) developed recurrence.

Conclusion: Combination of RND or MRND and radiotherapy is highly effective in controlling neck disease in controlled primary tumors.

Key words: Cervical nodal metastasis, Neck dissection, Radiotherapy

Author's Contribution $\quad$ Address of Correspondence

${ }^{1}$ Conception, synthesis, planning of research and manuscript writing Interpretation and discussion

${ }^{2,3}$ Data analysis, interpretation and

manuscript writing, Active participation in

data collection.

Cite this article. Umar MA, Ahmed J, Saqulain G. Efficacy/Validity of Neck Dissection and Radiotherapy for Cervical Nodal Disease - Clinicopathological Analysis. JIMDC.2018; 7(4):274279

\section{Introduction}

Head and neck tumors are quite common, ${ }^{1,2}$ majority being squamous cell carcinomas with laryngeal involvement being the commonest. ${ }^{3}$ In a local study variation in the prevalence was noted in different parts of the country. ${ }^{3}$ Also presentation with metastatic neck disease is quite common. ${ }^{4}$ The status of cervical lymph nodes with primary head and neck malignancy has vital

\section{Article info.}

Received: June 20, 2018

Accepted: November 10, 2018

\author{
Funding Source: Nil \\ Conflict of Interest: Nil
}

prognostic significance with increased incidence of distant metastases with nodal disease. ${ }^{5}$ This demands workup for cervical lymph node metastasis and thorough management of cervical nodal disease. One of the most widely used procedure conventionally was Radical Neck Dissection (RND), however in recent years treatment of neck disease in head and neck malignancy has been 
widely debated. RND, which was popularized by $\mathrm{Dr}$. Hayes Martin ${ }^{6}$ involves unblock removal of lymph nodes of lateral neck along with superficial and deep layers of deep cervical fascia, including submandibular, deep cervical, posterior triangle and supraclavicular nodes and lymphatics along with sternomastoid muscle, internal jugular vein and accessory nerve. ${ }^{7}$ Now surgeons are moving away from RND for No and N1 neck, and started performing modifications by preserving the accessory nerve or other non-lymphatic structures. However, the question remains that for advanced neck disease are modifications like Modified Radical Neck Dissection (MRND) with post-operative radiotherapy adequate. This has been agreed by some researchers ${ }^{8}$

Despite the bulk of literature available on the subject, lack of uniformity in connection with treatment strategies for neck disease still exist and also because there is dearth of such studies from this part of Pakistan, therefore, the present study is important.

\section{Patients and Methods}

This observational prospective study was conducted at Department of Otorhinolaryngology and Head and Neck Surgery of Pakistan Institute of Medical Sciences, Islamabad over a period of 16 months from February 2005 to June 2006.

Inclusion criteria was patients with controlled primary malignant tumor in the head and neck with cervical nodal metastases, of either gender and all age diagnosed and managed at the department. Exclusion criteria include patients who had un-resectable primary tumor and cases of cervical metastases with recurrence at primary site. Sampling was done through non-probability sampling technique. Total15 patients who met the inclusion criteria were included in the study. Chart reviews of these patients were done to acquire history and other clinical data including age, gender, site and histology of primary tumor. For neck metastases the level of lymph nodes, their size, mobility, whether ipsilateral, contralateral or bilateral was assessed and nodal status was recorded using UICC staging. ${ }^{9}$ All patients underwent FNAC examination to confirm metastases. CT scan was done in some patients to see the extent of the metastatic neck disease and treatment was planned accordingly.
Histopathology was confirmed by histopathology reports of the patients.

Out of total 15 patients, RND was performed on 3 patients, 7 patients underwent MRND and 2 patients underwent SupraOmohyoid neck Dissection (SND), while another 3 patients were treated with radiotherapy. All the patients followed up after treatment for minimum up to 1 year with special attention to neck node palpation to detect any recurrence.

Data was collected, tabulated and analyzed using Microsoft Excel Worksheet. Gender was presented by frequency and percentage. Mean, Median and Mode was calculated for age of patient at presentation. Variables like site and histology of primary tumor site, nodal status including level, mobility, FNAC, treatment and post treatment results were presented by frequency and percentage.

\section{Results}

Among total 15 cases, there was male preponderance with 11 males $(73 \%)$ and 4 females $(27 \%)$ with male to female ratio $M: F=2.75: 1$. Their age ranged from 45 to 75 years with mean age of 57.3 years (Table 1). Common tumor sites included Larynx in $5(33.3 \%)$ cases and tongue in $4(26.7 \%)$ cases (Table 2).

Examination revealed that most patients having nodal metastasis at level II, followed by level III. Nodes were mostly mobile. FNAC confirmed the presence of metastatic neck disease which was mainly squamous cell variety in $10(83.4 \%)$ cases. Total $12(80 \%)$ patients underwent neck dissection. While $3(20 \%)$ patients received radiotherapy (A dose of 66 Gy each), among them 2 were unfit for surgery and 1 refused surgery. Among surgical procedures MRND was the most common procedure done $47 \%$ (Table 2).

\begin{tabular}{|l|l|c|}
\hline \multicolumn{2}{|c|}{ Table 1: Demographic Data of Study Population } \\
$(\mathbf{n = 1 5 )}$
\end{tabular}




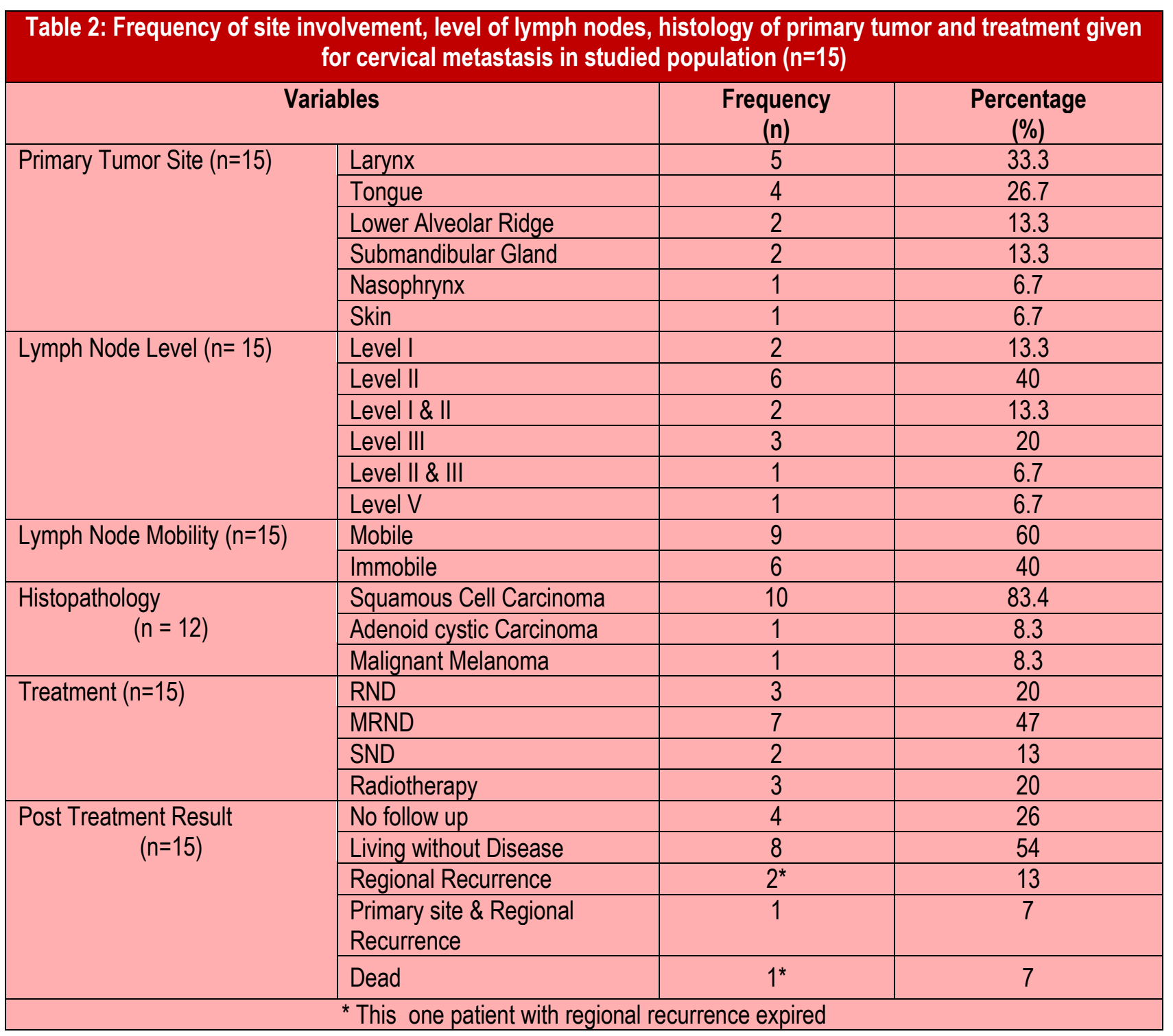

Minimum follow up was maintained for a year. Total $2(13 \%)$ patients developed recurrence in the neck (1 in MRND group, and the other 1 in radiotherapy group who later expired) in the absence of recurrent primary disease. In $1(7 \%)$ patient, the recurrence in the neck was associated with recurrent primary disease as well. All these patients developed recurrence within first 6 months. Therefore, total of 12 out of 15 necks $(80 \%)$ were controlled and total $3(20 \%)$ patients had recurrence. Total 8 patients $(54 \%)$ were living without loco regional disease with the longest follow up of 16 months for 1 patient, while $4(26 \%)$ were lost to follow up after first 6 months. However, one of these lost patients came for follow up but after the mentioned study period i.e. of one year (Table 2). Total 11 patients received postoperative radiotherapy, with a mean dose of 55 Gy (Range 30-66 Gy), only 2 patients received less than 50 Gy. Total $17 \%$
(2/12) of dissected necks were pathologically N1, 33\% (4/12) were N2a and 50\% (6/12) were N2b (Table 3).

\section{Discussion}

Head and neck cancers are common all over the world occupying $6^{\text {th }} 1$ and $8^{\text {th }}$ position ${ }^{2}$, among whole body cancers according to different authors, occurring in 560000 patients with 380000 deaths per year. ${ }^{10}$ These tumors being predominant in males are mostly seen between 50 to 70 years of age. ${ }^{4}$ Squamous cell carinomas (SSC) with laryngeal involvement are the commonest. ${ }^{3}$ According to Ridge JA et al, SSC account for $>90 \%$ head and neck tumors in the west ${ }^{4}$ and in a local study, Aziz F et al reported the frequency of SCC being the commonest $45.8 \%$, followed by lymphoma 


\begin{tabular}{|l|c|c|}
\hline \multicolumn{3}{|c|}{ Table 3: Clinical Versus Pathological Nodal } \\
Staging \\
\hline & $\begin{array}{c}\text { Clinical Stage } \\
(n=15)\end{array}$ & $\begin{array}{c}\text { Histo-Pathological } \\
\text { Stage ( } \mathbf{n = 1 2 )}\end{array}$ \\
\cline { 2 - 3 } & Number (n\%) & Number $(\mathrm{n} \%)$ \\
\hline N1 & $4(26.7)$ & $2(17)$ \\
\hline N2a & $8(53.4)$ & $4(33)$ \\
\hline N2b & $3(20)$ & $6(50)$ \\
\hline
\end{tabular}

(14.5\%), basal cell carcinoma (BCC), thyroid carcinoma $(10.5 \%$ each), salivary gland tumors $(8.80 \%)$, others being infrequent. ${ }^{3}$ In our study SSC topped the list (83.4\%) followed by adenoid cystic carcinoma and malignant melanoma. Site wise, laryngeal tumors are the commonest i.e., $53.5 \%$, followed by pharynx $18.7 \%$, tongue $10.71 \%$, oral cavity $4.4 \%$ and skin $2.6 \%$, being the least common. ${ }^{3}$ In the present study also larynx and tongue were the commonest sites with relative frequency of $33.3 \%$ and $26.7 \%$ respectively and skin being the least common with frequency of $6.7 \%$. Head and neck tumors show gross variations in incidence in different regions globally. Aziz $\mathrm{F}$ et al noted variation in the prevalence in different parts of Pakistan as well. ${ }^{3}$

Metastatic neck disease is also very common with $43 \%$ showing involvement of regional nodes, ${ }^{4}$ and this also drops survival by almost $50 \%$. Cervical nodal status with primary head and neck malignancy has vital prognostic significance demanding workup and thorough management of cervical nodal disease. ${ }^{11,12}$ RND was the most widely used procedure to deal with neck metastasis, however this has been widely debated. RND, which was popularized by Dr. Hayes Martin ${ }^{6}$, involves enblock removal of lateral neck nodes with superficial and deep layers of deep cervical fascia, including submandibular, deep cervical, supraclavicular and posterior triangle nodes and lymphatics along with sternomastoid muscle, internal jugular vein and accessory nerve ${ }^{7}$. According to Saurez, removal fibro fatty tissue of neck bearing lymph nodes, without sacrificing the non-lymphatic structures was oncologically sound. ${ }^{13}$ Also, for No and N1 nodal status, surgeons have started modifications of the procedure by preserving the accessory nerve or other non-lymphatic structures to minimize morbidity but to maintain oncologic efficacy. However, the question still remains that for advanced cases i.e., N2 or N3 (stage IV) which have worst prognosis, is MRND with post-operative radiotherapy adequate. This has been agreed by some researchers. ${ }^{8}$ It is important to note that modification with preservation of spinal accessory avoids the shoulder disability. ${ }^{14}$ Leipzig et al. ${ }^{16}$ and Sobel et al. ${ }^{14}$ have shown clear correlation between the amount of nerve dissection and degree of shoulder dysfunction. Even lesser dysfunction was noted when all the three i.e., nerve, muscle and vein were preserved during SND and functional neck dissection. ${ }^{15}$ Nerve sparing dissections result in significant, but temporary and reversible shoulder dysfunction, while RND is followed by profound and permanent one. ${ }^{16}$ Preservation of the spinal accessory nerve and if preserved along with sternocleidomastoid muscle, result in better shoulder function, protection of neck arteries and cosmesis. ${ }^{17,18}$ Therefore surgeons try to preserve accessory nerve etc., when oncologially feasible.

Postoperative radiation therapy is recommended for cases with large nodal metastasis and extranodal spread. However, a high incidence of local recurrence and distant metastasis is noted in these cases. Distant secondaries are seen in $10 \%$ cases of initial relapse, and $47 \%$ in cases with more than three positive nodes. ${ }^{19}$ Radiotherapy has also been claimed to have good results at some centers. In a study by Bernier and Bataini 20 achieved a 3-year nodal control rate for No tumours of 98 $\%$; for $\mathrm{N} 1,90 \%$; for $\mathrm{N} 2,88 \%$; and for $\mathrm{N} 3,71 \%$ when the primary site remained controlled.

Our neck control rate was of $100 \%$ (3/3) for RND and $86 \%(6 / 7)$ for MRND that are comparable to the international studies and it also supports the approach to nerve preservation, even in bulky N2 or N3 disease. In our study, radiotherapy alone for the neck disease was not as effective as surgery followed by radiotherapy and 2 of 3 cases who received radiotherapy alone developed neck recurrence, one of these 2 also developed recurrence at primary site. Studies by Richards et al ${ }^{21}$, Santos et al ${ }^{21}$, Pathak et al ${ }^{22}$, and Leemans et al ${ }^{23}$ as well as our study shows that comprehensive neck dissection (RND \& MRND) and postoperative radiotherapy has a high likelihood of controlling disease in the ipsilateral neck, as long as disease remains controlled at the primary site. 
In correlating our clinical and pathological staging, a number of patients were found clinically $\mathrm{N} 1$ but pathologically N2a and clinically N2a but pathologically N2b. Also around $50 \%$ of the necks are pathologically $\mathrm{N} 2 \mathrm{~b}$, suggesting that by the time a solitary mass becomes clinically greater than $3 \mathrm{~cm}$, probably metastasis to multiple nodes have already occurred. Based on this experience, a comprehensive neck dissection for N2 or greater disease and postoperative radiotherapy seems logical. Though in this study contralateral negative necks were treated with radiotherapy alone, however failure of control was not noted, indicating success of this approach. However, in contrast, Richards et al ${ }^{8}$, found contralateral neck failure in the absence of primary site disease in some patients and they suggested. SND of contra lateral negative neck Follow up with evaluation by physician is essential ${ }^{24}$ with special attention to neck palpation which has a sensitivity and specificity of 60$70 \%$, is essential element of management of these cases. Unfortunately, 4 cases were lost to follow up in this study. This study has significant importance since there is dearth of such studies from this part of the world, though cervical recurrence in is quite common here. The study highlights the importance of various surgical, radiotherapeutic or combined strategies, which can be adopted for the treatment of cervical metastasis.

\section{Conclusion}

Combination of RND and MRND with radiotherapy is highly effective in controlling neck disease in the absence of persistent or recurrent local disease. Also in our experience, MRND appears to be as effective as RND in controlling even advanced neck disease, which supports the preservation of the spinal accessory nerve whenever oncologically feasible.

\section{References}

1. Siegel RL, Miller KD, Jemal A. Cancer Statistics, 2017. CA Cancer J Clin. 2017; 67(1):7-30

2. Hakim M, Billan, S, Tisch U, Peng G, Dvrokind I, Marom $O$ et al. Diagnosis of head-and-neck cancer from exhaled breath. $\mathrm{Br} J$ Cancer.2011; 104(10): 1649-55.

3. Aziz F, Ahmed S, Malik A, Afsar A, Yusuf NW. Malignant Tumors of Head and Neck region - A retrospective analysis. J Coll Physicians Surg Pak 2001; 11(5):287-90.

4. Ridge JA, Mehra R, lango MN, Galloway T. Head and neck tumors. In: Pazdur R, Wagman LD, Camphausen KA, Hoskins WJ (eds), Cancer Management: A Multidisciplinary Approach Medical, Surgical and Radiation Oncology 12th edn., The Oncology Group: New York.2016

5. Ferlito A, Shaha AR, Silver CE, Rinaldo A, Mondin V. Incidence and sites of distant metastases from head and neck cancer. ORL J Otorhinolaryngol Relat Spec. 2001; 63(4):202-7.

6. Martin H, Del Valle B, Ehrlich H, Cahan WG. Neck dissection. Cancer 1951; 4(3):441-99.

7. Watkinson JC, Gaze MN, Wilson JA. Neck dissection. In: Stell and Maran's Head and Neck Surgery. 4th ed. London: Butterworth- Heinemann; 2000:215-32.

8. Richards BL, Spiro JD. Controlling advanced neck disease: efficacy of neck dissection and radiotherapy. Laryngoscope 2000; 110(7):1124 - 7 .

9. TNM classification of malignant tumours Sobin $L H$, Gospodarowicz M K, Wittekind Ch International Union against Cancer. 7th ed. Wiley-Blackwell publishing, 2009.

10. Global Burden of Disease Cancer Collaboration, Fitzmaurice C, Allen C, et al. Global, Regional, and National Cancer Incidence, Mortality, Years of Life Lost, Years Lived with Disability, and DisabilityAdjusted Life-years for 32 Cancer Groups, 1990 to 2015: A Systematic Analysis for the Global Burden of Disease Study. JAMA Oncol 2017; 3(4):524.

11. Chen CC, Lin JC, Chen KW. Lymph node ratio as a prognostic factor in head and cancer patients. Radiat Oncol. 2015; 10(1):181.

12. Park JO, Joo YH, Cho KJ, Kim MS. Lymph node density as an independent prognostic factor in nodepositive patients with tonsillar cancer. Head Neck. 2016;38(S1):E705-E711.

13. Suarez, $\mathrm{O}$. El problema de las metastasis linfáticas y alejadas en cancer de laringe e hipofaringe. Rev Otorrinolaring (Santiago) 1963 ; 23: 83-89.

14. Sobol S, Jensen C, Sawyer W, Costiloe P, Thong N. Objective comparison of physical dysfunction after neck dissection. Am J Surg 1985;150(4): 503-09.

15. Leipzig B, Suen JY, English J, Barnes J, Hooper M. Functional evaluation of the spinal accessory nerve after neck dissection. Am J Surg 1983;146(4): 52630.

16. Remmler D, Byers R, Sheetz A. A prospective study of shoulder disability resulting from radical and 
modified neck dissections. Head Neck Surg 1986;8(4):280-86.

17. Erisen L, Basel B, Irdesel J, Zarifoglu M, Coskun H, Basut 0 . Shoulder function after accessory nervesparing neck dissections. Head Neck 2004;26(11): 967-71.

18. Cuccia G, Shelley OP, Alcontres FS, Giannitrapani M, Soutar DS, Camilleri IG. Evidence of significant sternocleidomastoid atrophy following modified radical neck dissection type III. Plast Reconstr Surg. 2006; 117(1): 227-32.

19. Leemans CR, Tiwari R, Nauta JJP, van der Waal I, Snow GB. Regional lymph node involvement and its significance in the development of distant metastasis in head and neck carcinoma. Cancer 1993; 71(2): 452-56.

20. Bernier J, Bataini JP. Regional outcome in oropharyngeal and pharyngolaryngeal cancer treated with high dose per fraction radiotherapy: analysis of neck disease response in 1646 cases. Radiother Oncol 1986; 6(2):87-103.
21. Santos $A B$, Cernea $C R$, Inoue $M$, Ferraz $A R$. Selective neck dissection for node-positive necks in patients with head and neck squamous cell carcinoma: a word of caution. Arch Otolaryngol Head Neck Surg 2006;132(1):79-81.

22. Pathak KA, Das AK, Agarwal R, Talole S, Deshpande MS, Chaturvedi P, Pai PS, Chaukar DA, D'Cruz AK. Selective neck dissection (I-III) for node negative and node positive necks. Oral oncology. 2006;42(8):83741.

23. Leemans $C R$, Tiwari $R$, van der Waal I, Karim ABMF, Nauta JJP, Snow G. The efficacy of comprehensive neck dissection with or without postoperative radiotherapy in nodal metastasis of squamous cell carcinoma of the upper respiratory and digestive tracts. Laryngoscope 1990;100(11): 1194-98.

24. Agrawal A, deSilva BW, Buckley BM, Schuller DE. Role of the physician versus the patient in the detection of recurrent disease following treatment for head and neck cancer. Laryngoscope 2004; 114(2):232-35. 